\title{
Sport Activities Management in P.E Lesson for Physical Education Teachers (Obstacles, Solutions)
}

\begin{abstract}
Abdallah Abdel Halim Mohamed
Assistant professor at department of curriculum, teaching methods, training and sport movement science. faculty of P.E, University of Sadat City.
\end{abstract}

Abstract:

The aim of this research was to identify obstacles of Sport activities management during the implementation physical education teachers of P.E lessons. The researcher used the descriptive method in the survey style on a sample of P.E teachers in the government preparatory schools. The percentages and obstacles to the management of school activities in the educational process facing the teachers of the public preparatory schools during the implementation of P.E classes, and the most appropriate solutions through which to overcome these obstacles from the point of view of teachers.

Keywords: Sport activities, PE lesson, Obstacles

\section{Introduction}

The physical activity is an activity that educational works on the education of young people balanced and integrated education respects the emotional, social, physical and mental, by land, vol multi - sport areas under the supervision of specialized leadership is working to achieve the goals of sport activities, including contributing to the achievement of the overall objectives of raising the Riad Yeh in the stages of education The different. (Gazy Al Anzy, 2019. 18)

School sports play an important role in providing appropriate growth opportunities in the preparation of healthy, integrated physical, mental, psychological and social development, which is an important factor in the process of growth and development. (Mohamed Azmi, 2007. 20)
Physical

represents the smallest educational unit in the school curriculum, contributes to the formation of correct concepts of school sports. Organized school sport activities contribute to the ability of students to experience, understand and modify their behavior. The physical education teacher plays an important role in planning, organizing and managing sport activities. In achieving the objectives of physical education in general and the objectives of physical education in particular. (Zakia Ibrahim et al, 2010. 33)

The researcher believes that .. Despite the existence of technological means and modern media in the current era, which relies on short idea of self - learning learners .. but the teacher remains the basic infrastructure in Any system 
educational Without him No The educational process are properly; where Tto Stand effective educational system On Bezel Effectiveness And its adequacy And commitment in a Implementation of Approach And the study content which includes the sport activities associated with the courses. (Frost,-R-B., 2005. 66)

And through the work of a researcher at the teaching faculty, Department of Curriculum and Instruction and during the supervision of the education students the process of schools found that there are problems and obstacles facing the work area of physical education teacher, and that there are obstacles to the implementation of the programs of sport activities .. Based upon the importance emerged and the need to study This problem has become a reality in most educational sectors, if not entire , and try to find appropriate solutions.

Therefore, the researcher considers the importance of the need to conduct this study and study the actual reality of the difficulties and obstacles facing the teacher of physical education, which prevent the progress of work and the failure to achieve the desired objectives of the exercise of sport activities, and studying the reality of sport activities and its problems contribute to finding solutions that help To achieve the objectives of the educational process in general and the goals of physical education in particular.
Hence the idea of this study To determine the reality of sport activities in the course of physical education and to explain the reasons that lead to the inability or inability of the teachers of physical education to manage and organize sport activities in an effective manner during the implementation of physical education lessons, with the researcher to develop some guidance or solutions that can be followed to manage and organize sport activities in a way effective, and thus help workers and those on the school sports in general, to know the needs of students and teachers and then, according to the results of the study can help in good planning and preparing for the sports programs and school curricula and implemented based on Scientific results.

\section{Reseach Aims:}

This research aims to exposure in the reality of sport activities by clarifying obstacles to the management and organization of school sport activities facing the teachers of the second cycle of basic education during the execution of their lessons of physical education, with the development of solutions that can be followed to manage and organize sport activities in an effective manner.

\section{Reseach Questions:}

- What are the obstacles to the management and organization of school sport activities facing the teachers of the second cycle of basic education (teachers of government preparatory schools) 
During their implementation of physical education classes?

- What guidance can be used to effectively manage and organize sport activities?

\section{Methodology}

Method

The researcher used the descriptive method in the survey method in order to suit the nature, objectives and research questions .

Society and Research Sample:

The community research sample in the physical education teachers from the second episode of basic education stage prep school government in Giza Governorate in 2018/2019, And the sample included a number of (434) and teachers in 17 educational management.

\section{Tools:}

\section{1- Interview:}

Interviews were conducted with some teachers, mentors and principals in the field of education in order to collect the data that can be used to develop a general overview of the design of the questionnaire .

\section{2- Examination and analysis of documents and previous studies:}

The access to documents and records in order to collect and extract data for teachers of physical education and the Code of Education payroll directorate in Giza Governorate and educational departments have Alta seven for the academic year 2018/2019 m.

\section{3- Questionnaire :}

- Design of an open questionnaire: (Appendix 2)

The questionnaire included one open question: What are the obstacles to the management and organization of school sport activities facing the teachers of the second cycle of basic education During their implementation of physical education classes?

In order to identify all the problems related to the obstacles to the management and organization of school sport activities facing teachers of physical education .

- Open Questionnaire: The open questionnaire was presented to (34) teachers from the preparatory public schools in Giza governorate .

- Questionnaire obstacles to the management and organization of school sport activities: (Appendix 3)

$A$ - axes and balance of the questionnaire :

After identifying the axes (which were derived from the results of the open questionnaire), the researcher presented these axes to the experts (Appendix 1), And the percentage of agreement was calculated for each of the proposed axes of the obstacles to the management and organization of school sport activities, as shown in Table (1): 
Table ( 1 )Percentage of experts' agreement on the axes of the questionnaire on the obstacles of school sport activities

\begin{tabular}{clcc}
\hline No. & \multicolumn{1}{c}{ Constraints or problems } & $\begin{array}{c}\text { Number of } \\
\text { times agreed }\end{array}$ & $\begin{array}{c}\text { Rate the } \\
\text { agreement \% }\end{array}$ \\
\hline 1 & Lack of potential & 5 & $100 \%$ \\
\hline 2 & dispersion of attention & 5 & $100 \%$ \\
\hline 3 & Absence Frequent About Physical education classes & 5 & $100 \%$ \\
\hline 4 & $\begin{array}{l}\text { E. Non - response The disciples of the instructions of } \\
\text { the teacher }\end{array}$ & 5 & $100 \%$ \\
\hline 5 & Chaos And not the system & 5 & $100 \%$ \\
\hline 6 & the behavior Aggression & 5 & $100 \%$ \\
\hline 7 & the behavior The isolationist & 5 & $100 \%$ \\
\hline 8 & $\begin{array}{l}\text { Talk Non Appropriate during the implementation of } \\
\text { sport activities }\end{array}$ & 4 & $80 \%$ \\
\hline 9 & Non Bring Pupils sports clothes & 4 & $80 \%$ \\
\hline
\end{tabular}

B - Questionnaire obstacles to the researcher developed a number of the management and vocabulary that reflects the problems organization of school sport of handicaps management and activities:

Through all of the results of the that teachers face government junior open questionnaire and personal high schools, the number of problems interview and survey reference to were in the initial image (77) problem previous studies, books and scientific spread over a number (9) axes, as references No. $4(5,7-12,16,17,20)$, shown extension (3).

Table ( 2 )Topics and problems of the questionnaire in its preliminary form ( before experts)

\begin{tabular}{clc}
\hline No. & \multicolumn{1}{c}{ Constraints or problems } & $\begin{array}{c}\text { Number of vocabulary } \\
\text { (problems) }\end{array}$ \\
\hline 1 & Lack of potential & 9 \\
\hline 2 & Dispersion of attention & 9 \\
\hline 3 & Absence Frequent About Physical education classes & 17 \\
\hline 4 & $\begin{array}{l}\text { E. Non - response The disciples of the instructions of the } \\
\text { teacher }\end{array}$ & 9 \\
\hline 5 & Chaos And not the system & 4 \\
\hline 6 & the behavior Aggression Z & 13 \\
\hline 7 & the behavior The isolationist & 5 \\
\hline 8 & $\begin{array}{l}\text { Talk Non Appropriate during the implementation of sport } \\
\text { activities }\end{array}$ & 8 \\
\hline 9 & Non Bring Pupils sports clothes & 3 \\
\hline & Total & $\mathbf{7 7}$ \\
\hline
\end{tabular}

Table (3) Sample responses on the reality of school sport activities 
journal of Theories and Applications of physical education sport sciences

No.

\begin{tabular}{|c|c|c|c|c|c|c|}
\hline \multicolumn{3}{|c|}{ the problem } & \multirow{3}{*}{$\begin{array}{c}\text { Estimated } \\
\text { total }\end{array}$} & \multirow{3}{*}{$\begin{array}{c}\text { Relative } \\
\text { weight }\end{array}$} & \multirow[b]{2}{*}{$\mathbf{K a}^{2}$} & \multirow{3}{*}{ Ranking } \\
\hline $\begin{array}{c}\text { Highly } \\
\text { available }\end{array}$ & $\begin{array}{c}\text { Medium- } \\
\text { sized }\end{array}$ & $\begin{array}{c}\text { Not } \\
\text { available }\end{array}$ & & & & \\
\hline Fer. & Fer. & Fer. & & & & \\
\hline
\end{tabular}

Axis I: Lack of potential:

\begin{tabular}{|c|c|c|c|c|c|c|c|}
\hline 1 & 216 & 95 & 4 & 842 & $89.10 \%$ & 42.25 & 4 \\
\hline 2 & 220 & 70 & 25 & 825 & $87.30 \%$ & 45.62 & 5 \\
\hline 3 & 75 & 215 & 25 & 680 & $71.96 \%$ & 64.69 & 7 \\
\hline 4 & 307 & 6 & 2 & 935 & $98.94 \%$ & 49.67 & 1 \\
\hline 5 & 160 & 120 & 35 & 755 & $79.89 \%$ & 47.36 & 6 \\
\hline 6 & 305 & 8 & 2 & 933 & $98.73 \%$ & 36.69 & 2 \\
\hline 7 & 250 & 49 & 16 & 864 & $91.43 \%$ & 47.98 & 3 \\
\hline Total axis & 1533 & 563 & 109 & 5834 & $88.19 \%$ & 39.66 & the first \\
\hline \multicolumn{8}{|c|}{ The second axis: Dispersion of attention: } \\
\hline 8 & 160 & 99 & 56 & 734 & $77.67 \%$ & 41.25 & 5 \\
\hline 9 & 150 & 140 & 25 & 755 & $79.89 \%$ & 38.47 & 4 \\
\hline 10 & 80 & 120 & 115 & 595 & $62.96 \%$ & 36.59 & 9 \\
\hline 11 & 155 & 142 & 18 & 767 & $81.16 \%$ & 41.59 & 3 \\
\hline 12 & 66 & 190 & 59 & 637 & $67.41 \%$ & 41.21 & 7 \\
\hline 13 & 95 & 160 & 60 & 665 & $70.37 \%$ & 39.35 & 6 \\
\hline 14 & 203 & 95 & 17 & 816 & $86.35 \%$ & 46.57 & 2 \\
\hline 15 & 60 & 190 & 65 & 625 & $66.14 \%$ & 42.67 & 8 \\
\hline 16 & 210 & 90 & 15 & 825 & $87.30 \%$ & 45.87 & 1 \\
\hline Total axis & 1179 & 1226 & 430 & 6419 & $75.47 \%$ & 41.65 & Fifth \\
\hline \multicolumn{8}{|c|}{ Third Axis: Repeated absence About Physical education classes : } \\
\hline 17 & 160 & 140 & 15th & 775 & $82.01 \%$ & 46.28 & 4 \\
\hline 18 & 104 & 102 & 109 & 625 & $66.14 \%$ & 41.36 & 7 \\
\hline 19 & 95 & 102 & 118 & 607 & $64.23 \%$ & 39.52 & 10 \\
\hline 20 & 253 & 45 & 17 & 866 & $91.64 \%$ & 38.84 & 1 \\
\hline 21 & 40 & 60 & 215 & 455 & $48.15 \%$ & 39.65 & 16 \\
\hline 22 & 215 & 96 & 4 & 841 & $88.99 \%$ & 33.56 & 2 \\
\hline 23 & 160 & 120 & 35 & 755 & $79.89 \%$ & 31.79 & 5 \\
\hline 24 & 84 & 96 & 135 & 579 & $61.27 \%$ & 32.56 & 11 \\
\hline 25 & 50 & 40 & 225 & 455 & $48.15 \%$ & 39.64 & $16 \mathrm{~m}$ \\
\hline 26 & 42 & 62 & 211 & 461 & $48.78 \%$ & 36.99 & 14 \\
\hline 27 & 96 & 64 & 155 & 571 & $60.42 \%$ & 34.57 & 12 \\
\hline 28 & 102 & 99 & 114 & 618 & $65.40 \%$ & 41.85 & 8 \\
\hline 29 & 104 & 95 & 116 & 618 & $65.40 \%$ & 36.55 & $8 \mathrm{~m}$ \\
\hline 30 & 45 & 51 & 219 & 456 & $48.25 \%$ & 32.12 & 15th \\
\hline 31 & 205 & 96 & 14 & 821 & $86.88 \%$ & 32.50 & 3 \\
\hline 32 & 150 & 140 & 25 & 755 & $79.89 \%$ & 32.67 & $5 \mathrm{~m}$ \\
\hline 33 & 65 & 42 & 208 & 487 & $51.53 \%$ & 36.96 & 13 \\
\hline Total axis & 1970 & 1450 & 1935 & 10745 & $66.89 \%$ & 35.37 & Ninth \\
\hline
\end{tabular}

The fourth axis : no E. Students respond to the instructions of the teacher:

\begin{tabular}{cccccccc}
\hline 34 & 190 & 61 & 64 & 756 & $80.00 \%$ & 36.64 & 5 \\
\hline 35 & 195 & 55 & 65 & 760 & $80.42 \%$ & 34.38 & 3 \\
\hline 36 & 201 & 96 & 18 & 813 & $86.03 \%$ & 31.54 & 2 \\
\hline 37 & 65 & 52 & 198 & 497 & $52.59 \%$ & 36.22 & 8 \\
\hline 38 & 85 & 75 & 155 & 560 & $59.26 \%$ & 32.31 & 7 \\
\hline 39 & 218 & 85 & 12 & 836 & $88.47 \%$ & 34.18 & 1 \\
\hline 40 & 102 & 96 & 117 & 615 & $65.08 \%$ & 36.85 & 6 \\
\hline 41 & 150 & 142 & 23 & 757 & $80.11 \%$ & 35.64 & 4 \\
\hline 42 & 45 & 48 & 222 & 453 & $47.94 \%$ & 34.69 & 9 \\
\hline Total axis & $\mathbf{1 2 5 1}$ & $\mathbf{7 1 0}$ & $\mathbf{8 7 4}$ & $\mathbf{6 0 4 7}$ & $\mathbf{7 1 . 1 0} \%$ & $\mathbf{3 7 . 5 6}$ & VIII \\
\hline
\end{tabular}


journal of Theories and Applications of physical education sport sciences

\begin{tabular}{|c|c|c|c|c|c|c|c|}
\hline \multicolumn{8}{|c|}{ Id Dis } \\
\hline 43 & 145 & 127 & 43 & 732 & $77.46 \%$ & 39.45 & 2 \\
\hline 44 & 169 & 75 & 71 & 728 & $77.04 \%$ & 36.79 & 3 \\
\hline 45 & 217 & 86 & 12 & 835 & $88.36 \%$ & 34.90 & 1 \\
\hline 46 & 163 & 69 & 83 & 710 & $75.13 \%$ & 38.76 & 4 \\
\hline Total axis & 694 & 357 & 209 & 3005 & $50 \%$ & 38.64 & second \\
\hline \multicolumn{8}{|c|}{ Sixth Axis : Aggressive Behavior : } \\
\hline 47 & 147 & 96 & 72 & 705 & $74.60 \%$ & 36.78 & 7 \\
\hline 48 & 210 & 95 & 10 & 830 & $87.83 \%$ & 35.46 & 1 \\
\hline 49 & 195 & 49 & 71 & 754 & $79.79 \%$ & 35.42 & 2 \\
\hline 50 & 163 & 98 & 54 & 739 & $78.20 \%$ & 35.24 & 4 \\
\hline 51 & 191 & 53 & 71 & 750 & $79.37 \%$ & 36.65 & 3 \\
\hline 52 & 123 & 125 & 67 & 686 & $72.59 \%$ & 36.33 & 8 \\
\hline 53 & 105 & 160 & 50 & 685 & $72.49 \%$ & 36.31 & 9 \\
\hline 54 & 65 & 48 & 202 & 493 & $52.17 \%$ & 39.45 & 13 \\
\hline 55 & 120 & 124 & 71 & 679 & $71.85 \%$ & 34.77 & 11 \\
\hline 56 & 142 & 68 & 105 & 667 & $70.58 \%$ & 45.89 & 12 \\
\hline 57 & 143 & Games & 93 & 680 & $71.96 \%$ & 41.65 & 10 \\
\hline 58 & 160 & 99 & 56 & 734 & $77.67 \%$ & 40.25 & 5 \\
\hline 59 & 123 & 152 & 40 & 713 & $75.45 \%$ & 39.41 & 6 \\
\hline Total axis & 1887 & 1246 & 962 & 9115 & $74.20 \%$ & 39.65 & VI \\
\hline
\end{tabular}

Seventh axis : isolation behavior :

\begin{tabular}{cccccccc}
\hline 60 & 150 & 125 & 40 & 740 & $78.31 \%$ & 37.45 & 2 \\
\hline 61 & 146 & 164 & 5 & 771 & $81.59 \%$ & 36.62 & 1 \\
\hline 62 & 93 & 89 & 133 & 590 & $62.43 \%$ & 34.61 & 4 \\
\hline 63 & 140 & 126 & 49 & 721 & $76.30 \%$ & 33.23 & 3 \\
\hline 64 & 94 & 86 & 135 & 589 & $62.33 \%$ & 33.20 & 5 \\
\hline Total axis & $\mathbf{6 2 3}$ & $\mathbf{5 9 0}$ & $\mathbf{3 6 2}$ & $\mathbf{3 4 1 1}$ & $\mathbf{7 2 . 1 9 \%}$ & $\mathbf{3 9 . 8 6}$ & Seventh \\
\hline
\end{tabular}

Eighth Axis : Speaking Non Appropriate during the implementation of school activities :

\begin{tabular}{cccccccc}
\hline 65 & 195 & 89 & 31 & 794 & $84.02 \%$ & 34.65 & 3 \\
\hline 66 & 105 & 85 & 125 & 610 & $64.55 \%$ & 32.36 & 7 \\
\hline 67 & 175 & 102 & 38 & 767 & $81.16 \%$ & 33.30 & 4 \\
\hline 68 & 208 & 102 & 5 & 833 & $88.15 \%$ & 32.12 & 1 \\
\hline 69 & 210 & 81 & 24 & 816 & $86.35 \%$ & 33.45 & 2 \\
\hline 70 & 163 & 93 & 59 & 734 & $77.67 \%$ & 39.57 & 5 \\
\hline 71 & 110 & 97 & 108 & 632 & $66.88 \%$ & 38.45 & 6 \\
\hline 72 & 95 & 85 & 135 & 590 & $62.43 \%$ & 37.15 & 8 \\
\hline Total axis & $\mathbf{1 2 6 1}$ & $\mathbf{7 3 4}$ & $\mathbf{5 2 5}$ & $\mathbf{5 7 7 6}$ & $\mathbf{7 6 . 4 0} \%$ & $\mathbf{3 6 . 8 5}$ & the fourth \\
\hline Axis of the ninth: Non Bring students sports clothes : & & & & \\
\hline 73 & 210 & 95 & 10 & 830 & $87.83 \%$ & 39.67 & 1 \\
\hline 74 & 194 & 103 & 18 & 806 & $85.29 \%$ & 40.96 & 2 \\
\hline 75 & 94 & 85 & 136 & 588 & $62.22 \%$ & 41.75 & 3 \\
\hline Total axis & $\mathbf{4 9 8}$ & $\mathbf{2 8 3}$ & $\mathbf{1 6 4}$ & $\mathbf{2 2 2 4}$ & $\mathbf{7 8 . 4 5} \%$ & $\mathbf{4 0 . 5 7}$ & the third \\
\hline Total questionnaire & $\mathbf{1 0 8 9 6}$ & $\mathbf{7 1 5 9}$ & $\mathbf{5 5 7 0}$ & $\mathbf{5 2 5 7 6}$ & $\mathbf{7 4 . 1 8 \%}$ & $\mathbf{4 0 . 6 9}$ & \\
\hline
\end{tabular}

$\mathrm{P}<0.05$

\section{Discussion}

As for the first question, which states : What are the obstacles to the management and organization of school sport activities facing the teachers of the second cycle of basic education during the implementation of physical education classes? Where 
the answer is clear by discussing the following:

It is seen from the table (13) that the research sample on the axis of potential phrases views ranged percentage of them between $79.89 \%$ : $98.94 \%$, and phrases that reflect the special reasons which lead to the lack of vocabulary The teachers of physical education to manage and organize sport activities in an effective manner are the words $(1,2,4,5,6,7)$ where the percentage came from $79.89 \%$ to $98.94 \%$.

This refers to the difficulty of work as a result of inadequate tools and equipment in proportion to the number of pupils during the implementation of physical education lesson, as it indicates that the tools and sports available devices do not fit with some mathematical approaches that need great potential requirements, and lack of sufficient know - how for students on how to use the tools And sports equipment during the implementation of the lesson, which leads to the suspension or disruption of the lesson, as well as the lack of alternative places to implement the lesson in bad weather conditions, and the lack of educational means Help to implement the lesson of physical education, as well as the lack of means of measurement of the school, which leads to the difficulty of the teacher to evaluate the students .

All previous findings are consistent with the study of both "
Alya Abd-Ghani, 2000" However, there is a lack of material and human resources, the lack of tools and instruments for measurement in schools, the tools available are not commensurate with the numbers of students, and the study "Schliemann, 2000) to him in Los Angeles is not a decision For the construction and construction of classrooms unless there is an area of 950 meters to design the playgrounds of sport activities in the school for their interest in sports education and their knowledge of sports education in the development of the integrated personality of young people, as well as study "Osama Ibrahim, 2002" Which indicated the need to increase financial dependence to overcome the lack of material resources, and the potential to provide the necessary tools for the exercise of physical activity and devices, and the study of " Soha A. Fattah, 2003), "Mohammed Abdel-Hamid, 2011"In that there is a lack of potential sports equipment deficit, and also includes a deficit reduction in the number of physical education teachers in schools.

The researcher explained that these results indicate that the reasons for dispersion of attention or lack of attention of students during the implementation of the lesson of physical education is due to activities that are not exciting and exciting in the eyes of students cause distraction and weaken the ability to follow and focus 
( focus on certain activities, For example ).

The researcher also points out that the reasons for non-infection or distraction of students due to the presence of external stimuli During the implementation of physical education classes, and of the reasons for lack of attention is the lack of pupils guidance given to him by the teacher 's commitment, or that the student fails to implement sport activities as they should, and therefore the student is having difficulty continuing to focus while performing the tasks assigned to them or Even during play, which ultimately leads to the failure of the student to focus on details or make mistakes due to indifference during the performance of sport activities, and therefore finds that the researcher does not Must for teachers of physical education to achieve a thorough understanding of the factors which affect $Z$ in $E$. Ntbah pupils and ways to improve and reduce levels of E. Anmalat dispersion.

And consistent with the above study , "Rehab G., 2004" That the reasons for not paying attention to pupils are the lack of commitment of students to the guidance given to him by the teacher, and the existence of activities that are not attractive to students .

The views of the sample of the research on the total of the questionnaire terms ranged from
$66.89 \%$ to $88.19 \%$ in the third and first axes respectively. The axes that express the vocabulary for the reasons for the failure of the teachers of physical education To manage and organize sport activities in an effective manner are the axes $(1,2,5,8,9)$ where the percentage is from $75.47 \%$ to $88.19 \%$.

This shows that the general ranking of the total axes of the reality of school sport activities to reach the axis of potential in the first order among the axes by $88.19 \%$, While the focus of a thousand came Ody And not The system ranked second with a percentage of $79.50 \%$, And the center of sportswear in the third ranking by $78.45 \%$, And in the fourth place the focus of talking during the implementation of sport activities by $76.40 \%$, And $\mathrm{V}$ axis distraction attention $75.47 \% \%$, Came the axis of behavior $\mathrm{N} \mathrm{Z}$, followed by Alta behavior Isolationist in the sixth and seventh respectively by $74.20 \%$, $72.19 \%$ Respectively, and in the eighth ranking it was not the focus of the $\mathrm{E}$ response to the instructions of the teacher by $71.10 \%$, And finally in the ninth place the absence axis For physical education classes by 66.89 $\%$.

As for the second question, which states : What guidance can be used to effectively manage and organize sport activities?

- Do not expand In the construction of buildings and increase 
Chapters on Calculation of stadiums .

- Exercises to lengthen the period Observe e, where the lack of pupils who suffer from the dispersion of attention to the ability to deal with the changes that appear around them even if they are positive changes, and that they need to be trained to organize their time and exploited in the performance of assigned its tasks, which leads to the lengthening Period of attention .

- Expand the contact base so that the school can identify the social, economic, health and psychological conditions of students .

- The teacher's insistence on the student's response to his instructions directly and firmly .

- Training the student to obtain the skills of cleanliness and order, which makes them maintain the cleanliness and arrange the school playgrounds .

- Develop and promote students' social behavior and encourage social life among them .

- Recognize aspects of isolation behavior at an early stage before this behavior is exacerbated because treatment $\mathrm{Be}$ easier whenever you discover the features early on.

\section{Conclusions}

Difficulty working due to insufficient instruments and equipment in proportion to the numbers of students during the implementation of the lesson of sports education .

- The available sports equipment and devices do not suit the requirements of some sports curricula that need great potential

- Activities that are not exciting and exciting to the pupils cause distractions and weaken their ability to follow and focus .

\section{Recommendations}

- Work on adequacy Tools and devices to suit the numbers of pupils during implementation Physical education lesson .

- Cooperation between the school administration and the teacher of physical education in the needs of sports tools and devices .

\section{References}

1 - Ahmed Mohamed Gabr : "Evaluation of the program of physical education for secondary schools, technical Dakahlia Governorate" unpublished Master thesis, Faculty of Physical Education, Mansoura University 2010.

2 - Osama Ahmed Ibrahim : " Evaluation of sports activities in schools in the preparatory stage of boys in the province of Sharkia " Master, Faculty of Physical Education Boys, Zagazig University $2002 \mathrm{~m}$.

3 - E. Lehman Mohamed Rabie : " Analytical study of the objectives of physical education curricula in 
basic education in the Arab Republic of Egypt " Master Thesis, Faculty of Physical Education, Tanta University , 2004.

4 - Ayman Ahmed Abdul Rahman : " obstacles to the practice of physical activity prep stage pupils Azhar institutes Qalyoubia " Master Thesis, Faculty of Physical Education, University of Banha 2013.

5 - Ayman Ali Osman : " the school sport 's for $m$ primary flight Qaliubiya province, " Sports College of Education, University of Banha 2017.

6 - Mr. Ihab Abdul Ilah : " Evaluation of physical education curricula in secondary schools experimental sports eastern province of " Master Thesis , Faculty of Physical Education, Mansoura University , 2005.

7 - Soha A. Fattah: " Evaluative organizational climate for sports education in schools prep sports study " Master Thesis, University of Tanta 2003 .

8 - Rehab Adel Gabal: " Study calendar problems facing pupils during the preparatory phase of the implementation of the Education studied sports " Master Thesis, Faculty of Physical Education, University of Menoufiya 2004.

9 - Zakia Ibrahim Kamel, $\mathrm{n}$ and Ibrahim Shaltout, Mervat on Khvaj of : Methods of teaching in the education of sports - the basics of teaching education sports, art radiation printing press, i 2 , Alexandria 2010.

10 - Tariq Aa' Zim Shamekh : " The reality of school sports schools in the city of Riyadh and its role in athletic achievement " College of Education, the Riad Yeh, Riyadh, King Saud University, Saudi Arabia 2006.

11 - Abdullah Mohammed Khalil : " the study of analytical and administrative constraints faced by the teachers of Physical Education " Master Thesis, Faculty of Physical Education, University of Menoufiya 2004.

12 - Essam El Din Metwally Abdullah : Methods of Teaching Physical Education between Theory and Practice , Aalam Foundation Sports For publishing and Dar AlWafaa for printing, Alexandria $2019 \mathrm{~m}$.

13 - Aqil Khalil Nasser : " Sports school activities and their role in revealing aspects of aggressive behavior and limit the " Journal of Human Sciences, Volume 22 , Issue 5 , Iraq $2014 \mathrm{~m}$.

14 - Alya Abd-Ghani : " Curriculum Design an experimental study proposed sports education for the preparatory phase " PhD thesis, Faculty of Physical Education Girls, Helwan University 2001.

15 - Gazy Al Anzy : the concept of sports activity and orientation programs , physical education sports library, Saudi Arabia 2019 
m.

Available

in

https://www.bdnia.com/?p=774

16 - Ghanem Al Z girded : " An analytical study of the reality of the State of Kuwait Sports School " Master Thesis, Faculty of Physical Education for Boys, Zagazig University 2007.

17 - Yolk D Abdul Hamid Abdo : " evaluating the practice of physical activity programs for the preparatory phase of the eastern province of Al - Azhar institutes " Master Thesis, Faculty of Physical Education, University of Banha 2011.

18 - Mohamed Azmi : Methods of development and implementation of the physical education lesson in basic education between theory and practice, facility knowledge, $\mathrm{i}$ 2 , Alexandria 2007.

19 - Key Ahh D Arifi : " Executive Program for Physical Education stage education calendar pain mediated Paljmahrih Libyan Master Thesis, Faculty of Physical Education for Boys, Zagazig University 2006.

20 - Moss Z Mohammed Abbas : " An evaluation study of the reality of school sports in light of recent trends for the development of the United Arab Emirates, " the International

Scientific

Conference, Faculty of Physical Education for Boys, Alexandria University , 2008.

21 - Yasser Abdalh Med Ahmed : " The role of content posted $Z$ curriculum of physical education and teachers in the health aspects give pupils the second cycle of basic education in the Arab Republic of Egypt " Master Thesis, Faculty of Physical Education, University of Zagazig 2008.

22 - Dijol Alain: Sports co en milieu scolaivre, des stages amicaleaunouvebac, universities rene desecraters, bibiothque URF, Sports, 2003.

23 - Frost,-R-B. Psychological Concepts applied to Physical Education and Coaching addision, Wesley P.co, p. 66, 2005.

24 - http://alyaseer.net/vb/showthre ad.php? $\mathrm{t}=14796$

25 - Morgan, Philip; Hansen, Vibeke: Recommendations to Improve Primary School Physical Education: Classroom Teachers' Perspective, Journal of Educational Research, v101 n2 Nov-Dec. 2017. 26 - Rehab Adel Gabal, Abdallah A. Mohamed Aly. Designing a physical environment measure according to the quality standards and education accreditation for primary school. The international scientific Journal of Physical Education and Sport Sciences (ISJPESS), NSSN 24003, Print issn: 2356-9565, Online issn: 2356-9573, Faculty of Physical Education for Men, Helwan University, April 2016.

27 - Schliemann Elton dale: Outdoor Physical Education Facilities, Journal - Article, 2000 